\title{
MODALIDADE DE ENSINO NA EDUCAÇÃO SUPERIOR: um estudo comparativo entre determinantes da escolha discente pelo ensino presencial versus EaD
}

\author{
Djanda Coelho de Assis \\ FACAPE \\ djandacoelho@hotmail.com \\ Josaias Santana dos Santos \\ FACAPE \\ josaias@yahoo.com.br \\ Florisvaldo Cunha Cavalcante Júnior \\ IFSERTÃO-PE \\ junior.ccavalcante@yahoo.com.br \\ João Eudes de Souza Calado \\ UNIVASF \\ eudes_calado@yahoo.com.br
}

\section{RESUMO}

O presente artigo objetivou pesquisar quais os determinantes na escolha da Instituição de Ensino Superior, presencial ou à distância, para cursar Ciências Contábeis em Petrolina-PE e Juazeiro-BA. Essa pesquisa quanto aos objetivos é classificada como descritiva e a abordagem predominantemente quantitativa. Foi aplicado um questionário presencialmente aos alunos que cursavam do $1^{\circ}$ ao $3^{\circ}$ período de Ciências Contábeis, em duas instituições da modalidade presencial e duas instituições da modalidade a distância. O questionário foi dividido em duas partes, sendo a primeira, o perfil dos alunos e a segunda, 12 variáveis determinantes, cada uma recebeu uma escala do tipo Likert de 5 pontos. A amostra foi de 183 alunos, portanto uma amostra representativa. O perfil dos estudantes é $52 \%$ do sexo feminino, $70 \%$ têm entre 17 e 26 anos, $84 \%$ cursaram o ensino médio em escola pública e $68 \%$ dos respondentes têm renda familiar de até 3 salários mínimos. As variáveis mais influentes para a escolha da IES na modalidade presencial são: nome da instituição no mercado, preferência própria, tempo para estudo e frequência das aulas, corpo docente e qualidade de ensino, grade curricular do curso e facilidade de ingresso na instituição e, na modalidade à distância, as variáveis influentes na escolha são: preferência própria, nome da instituição no mercado, grade curricular do curso, localização da instituição, tempo para estudo e frequência das aulas e segurança.

Palavras-chaves: Instituições de Ensino Superior. Curso de graduação. Ensino presencial. Ensino a Distância. 
TEACHING MODALITY IN HIGHER EDUCATION: a comparative study between the key factors of student choice for in-classroom education versus EaD

\begin{abstract}
This article aimed to research what are the determinants factors in the choice for the Higher Education Institution, in person or at a distance, to study Accounting Sciences in Petrolina-PE and Juazeiro-BA. This research regarding its objectives is classified as descriptive and the approach is quantitative. A face-to-face questionnaire was applied to students from the 1st to 3rd period of Accounting Sciences, in two institutions of face-to-face modality and two institutions of distance modality. The questionnaire was divided into two parts, the first being the student profile and the second 12 determining variables, each received a 5 -point Likert scale. The sample was composed by 183 students, therefore a substantial sample. The profile of the students is $52 \%$ female, $70 \%$ are between 17 and 26 years old, $84 \%$ attended high school in a public school and $68 \%$ of respondents have a family income of up to 3 minimum wages. The most influential variables for choosing IES in the face-to-face modality are: name of the institution in the market, personal preference, time for study and frequency of classes, faculty and teaching quality, course curriculum and ease of entry into the institution, and in the distance modality, the influential variables in the choice are: personal preference, name of the institution in the market, course curriculum, location of the institution, time for study and frequency of classes and security.
\end{abstract}

Keywords: Higher Education Institutions. Graduation course. Face-to-face teaching. Distance learning.

\title{
MODALIDAD DE ENSEÑANZA EN EDUCACIÓN SUPERIOR: un estudio comparativo entre determinantes de la elección discente de la enseñanza presencial versus EaD
}

\section{RESUMEN}

Este artículo tuvo como objetivo investigar cuáles son los determinantes en la elección de la Institución de Educación Superior, de manera presencial o a distancia, para estudiar Ciencias Contables en Petrolina-PE y Juazeiro-BA. Esta investigación sobre los objetivos se clasifica como descriptiva y el enfoque es cuantitativo. Se aplicó un cuestionario, presencialmente a estudiantes del $1^{\circ}$ al $3^{\circ}$ período de Ciencias Contables, en dos instituciones de la modalidad presencial y dos instituciones de la modalidad a distancia. El cuestionario se dividió en dos partes, la primera siendo el perfil del alumno 
y la segunda, 12 variables determinantes, cada una recibió una escala Likert de 5 puntos. La muestra fue de 183 estudiantes, por lo tanto, una muestra representativa. El perfil de los estudiantes es 52\% femenino, el $70 \%$ tiene entre 17 y 26 años, el $84 \%$ asistió al bachillerato en una escuela pública y el $68 \%$ de los encuestados tiene un ingreso familiar de hasta 3 salarios mínimos. Las variables más influyentes para la elección de IES en la modalidad presencial son: nombre de la institución en el mercado, preferencia personal, tiempo de estudio y frecuencia de clases, calidad docente y docente, currículo del curso y facilidad de ingreso a la institución, y en la modalidad a distancia, las variables influyentes en la elección son: preferencia personal, nombre de la institución en el mercado, plan de estudios del curso, ubicación de la institución, tiempo de estudio y frecuencia de clases y seguridad.

Palabras clave: Instituciones de educación superior. Curso de graduación. Enseñanza presencial. La educación a distancia.

\section{INTRODUÇÃO}

O cenário educacional passou por inúmeras mudanças nas últimas décadas e não foi diferente com as Instituições de Ensino Superior (IES), tendo em vista a concorrência acirrada na oferta de cursos, onde as instituições vistas como prestadoras de serviços estão mais preocupadas com qualificação profissional, custos acessíveis e publicidade (ALESSIO; DOMINGUES e SCARPIM, 2013).

Mondini et al. (2014) destacam que o aumento na oferta de cursos e o acirramento na concorrência exigem das IES dedicação maior na tarefa de atrair os alunos interessados em formação superior. Para os autores, o crescimento na oferta se deu principalmente devido à expansão dos cursos na modalidade à distância.

Na opinião dos alunos, observada na pesquisa de Schinaider et al. (2016), as razões para cursar o ensino superior são diversas, entre elas a necessidade de uma maior qualificação e, para isso, o ensino precisa ter qualidade para que possa oferecer uma boa formação profissional, tendo em vista a concorrência no mercado de trabalho.

O estudo de Alonso (2010) aponta que a escolha do curso universitário é de extrema importância, demandando uma análise profunda sobre seus desejos. Esse processo ocorre na adolescência e isso carece de apoio social; assim, essa decisão torna-se mais assertiva, com as reais possibilidades e perspectivas.

Conforme Andrade e Araujo (2011), as Instituições de Ensino Superior devem conhecer as necessidades e interesses dos consumidores educacionais, para potencializar as estratégias de marketing e propaganda, procurar avanços tecnológicos dentro do âmbito educacional e métodos para satisfazer seus clientes. 
Considerando a importância da escolha da IES pelos consumidores educacionais e que não foram observados estudos que abordam determinantes que influenciam a escolha pela IES para cursar Ciências Contábeis, o estudo em tela questiona: quais são os determinantes na escolha da Instituição de Ensino Superior, presencial ou à distância, para cursar Ciências Contábeis em Petrolina-PE e Juazeiro-BA?

O objetivo é identificar os determinantes que influenciam a escolha da Instituição de Ensino Superior, presencial ou à distância, para cursar Ciências Contábeis em Petrolina-PE e Juazeiro-BA, a fim de apontar informações relevantes para a gestão das IES, importante para a satisfação de quem busca e quem fornece educação.

A pesquisa justifica-se pelo fato de ser um tema pouco pesquisado e pela relevância para as IES de Ciências Contábeis, onde poderão identificar as preferências dos estudantes e/ou possíveis falhas na oferta do curso.

Para Alessio; Domingues; Scarpim (2013), pesquisas como essa podem auxiliar as Instituições de Ensino Superior a identificar suas carências com relação aos desejos dos estudantes, podendo priorizar os aspectos mais exigidos, questões sobre a estrutura física, qualidade do ensino, entendendo o que impulsiona no momento da escolha pela instituição responsável por sua graduação.

\section{REFERENCIAL TEÓRICO}

\subsection{Oferta e demanda das instituições de ensino superior}

O aumento desenfreado na abertura de novas Instituições de Ensino Superior, principalmente na modalidade à distância, cresceu ainda mais a concorrência em ambas as modalidades de ensino e exigiu das IES mensalidades mais atraentes, maior divulgação da marca no mercado, gestores mais capacitados, melhor infraestrutura e relacionamento harmonioso entre os participantes (ALESSIO; DOMINGUES; SCARPIM, 2013).

Domingues et al. (2016) reforçam que "as instituições precisam de mais empenho e estratégias para conquistar os estudantes e posteriormente conseguir mantê-los".

Nos últimos anos, o número de instituições de ensino superior teve um grande salto e, de 2001 a 2011, teve um aumento de 137\% (TANEGUTI, 2013). Devido a esse grande avanço, os estudantes passaram a sentir mais dificuldade na escolha, pois existem várias possibilidades, inclusive em relação à modalidade; o presencial, por exemplo, está perdendo espaço para o ensino a distância (RAMOS, SANDER e PRADO 2013).

Contudo, segundo Alessio, Domingues e Scarpim (2013), a rede de ensino privada necessita desenvolver novas habilidades e meios de abordagem com 
o objetivo de atrair e conquistar os alunos. Para Scharf e Scarpim (2014), um dos melhores resultados trazidos pela concorrência foi a profissionalização da gestão e dos professores, principais responsáveis pela atração e permanência dos estudantes nas IES.

Nesse cenário, nota-se o acirramento mercadológico da educação. As IES como prestadoras de serviços e os alunos como clientes causam maior competitividade na oferta de ensino de qualidade, com bons professores e estrutura organizada (ALESSIO; DOMINGUES; SCARPIM, 2013).

\subsection{Aspectos que determinam o ingresso na instituição}

Na literatura, são poucos os estudos sobre os determinantes que levam os estudantes a escolher determinada IES para formação superior, informação preciosa para as instituições que estão concorrendo por espaço no mercado educacional (RAMOS; SANDER; PRADO, 2013).

Segundo Bossa (2014), o consumidor no momento de comprar um produto ou serviço avalia os riscos da compra e também os riscos da decisão. No âmbito educacional, ocorre da mesma forma, pois os estudantes avaliam o custo da formação e também o retorno financeiro. Reis e Lobler (2012) apontam que as pessoas procuram trabalhar com o menor número de possível de variáveis de escolha, para assim propiciar mais tranquilidade no processo decisório.

Amaioria dos estudantes procura uma IES que possibilite maior crescimento profissional e rentabilidade financeira. Essa escolha pode ser influenciada pelo custo da mensalidade, o nome da instituição no mercado e a grade curricular, pois essas características são as que realmente importam (ALESSIO, DOMINGUES e SCARPIM, 2013).

Por outro lado, Ramos, Sander e Prado (2013) identificaram que os atributos que mais influenciam na escolha de uma instituição é a qualidade de ensino e aceitação da instituição no mercado de trabalho.

Uma questão relevante considerada por Reis e Lobler (2012) é a possibilidade de comparar as IES, assim o estudante pode escolher a que melhor se adeque à sua expectativa. No entanto, Bossa (2014) diz que as pessoas em todos os momentos fazem escolhas de todos os níveis. Há escolhas que demandam tempo, mas também existem as automáticas sem preocupação com as consequências.

A comparação entre os nomes das instituições no mercado, os valores da mensalidade e disponibilidade do serviço, principalmente a maneira de conquistar o consumidor educacional, são as principais variáveis que os consumidores educacionais levam em consideração no momento de sua decisão, segundo (SCHINAIDER et al., 2016). 


\subsection{Relação do processo decisório com as variáveis socioeconômicas}

O aluno consumidor passou a observar a educação a distância como possibilidade, considerando como interessantes a relação custos e riscos; portanto, a importância de conhecer o consumidor e entender suas expectativas. (BRITO et al. 2016).

No Brasil, estudos sobre os critérios usados pelos estudantes na escolha pela IES são embrionários e as instituições precisam ter o conhecimento dos seus pontos fortes e prontos fracos. Ramos, Sander e Prado (2013) dizem que quem oferta um serviço ou produto tem grande interesse em conhecer os determinantes no processo decisório do ser humano.

Segundo Bergano et al. (2008), com o mercado mais competitivo, as IES encontram dificuldades para conquistar novos alunos e manter os já existentes. Para os autores, a falta de melhoria no marketing das instituições causa um bombardeio de informações, que são refletidas em mais dúvidas na escolha pela instituição.

A literatura aponta que diferentes fatores podem influenciar a escolha das áreas de estudo, como exemplos: cultura familiar, crença religiosa e as convicções políticas (JORDANI et al., 2014). O estudo de Bossa (2014) demonstrou que nas famílias com maior poder aquisitivo, o valor da mensalidade e localização das IES não é uma preocupação, diferente das famílias de baixo poder aquisitivo.

\subsection{Modalidade presencial X Modalidade a distância}

A educação a distância está se expandindo cada vez mais, adquirindo importância no processo educacional e colaborando com a formação superior em diversas áreas (PORTUGAL et al., 2013).

Para Schinaider et al. (2016), ainda é preciso entender as dificuldades encontradas como a evasão, insatisfação com o ensino, falta de comprometimento dos discentes e docentes e também o preconceito social dos cursos a distância.

O estudo de Mondini et al. (2014) destaca que o maior interesse pelos cursos EaD é por conta das aulas ocorrerem apenas uma vez na semana, devido à carência de tempo para cursar o ensino presencial. Puerta e Amaral (2008) dizem que o ensino presencial tem a vantagem do retorno rápido pelo professor e a desvantagem é a falta de flexibilidade.

A modalidade a distância surgiu no Brasil para democratizar o ensino e inserir um número maior de estudantes no ensino superior, pois era uma demanda social, já que muitas pessoas não tinham acesso à formação (NASCIMENTO et al., 2014). Para Alonso (2010), houve a necessidade do poder público intervir para que 
essa oferta ocorresse, principalmente a partir da modalidade a distância, porém essa modalidade causa diversas discussões.

Portugal et al. (2013) apontaram que os consumidores educacionais da EaD consideram mais relevantes na modalidade: a flexibilidade, custo baixo e comodidade.

\section{METODOLOGIA}

A pesquisa quanto aos seus objetivos é classificada como descritiva, pois se trata de estudo, análise e interpretação dos fatos sem interferência do pesquisador. A pesquisa descritiva caracteriza-se como um estudo interposto entre a pesquisa exploratória e a explicativa, pois não é tão iniciante como a primeira e nem tão avançada como a segunda (BEUREN, 2006).

A abordagem da pesquisa é predominantemente quantitativa, pois prioriza apontar numericamente a frequência e a intensidade dos comportamentos dos indivíduos de um determinado grupo ou população. Diferentemente da pesquisa qualitativa, a pesquisa quantitativa é caracterizada pelo uso de instrumentos estatísticos, desde a coleta até o tratamento dos dados (BEUREN, 2006).

A coleta de dados foi realizada através de questionário aplicado presencialmente aos alunos que cursam entre $01^{\circ}$ e $\circ 3^{\circ}$ períodos, nas Instituições de Ensino Superior das modalidades presencial e a distância, de Ciências Contábeis em Petrolina-PE e Juazeiro-BA. O questionário foi dividido em duas partes. A primeira parte são perguntas sobre o perfil dos alunos, como: idade, sexo, período do curso, modalidade de ensino, categoria que cursou ensino médio, atuação profissional, renda familiar e nível de formação dos pais.

$\mathrm{Na}$ segunda parte, estão as variáveis influenciadoras, onde os alunos apontam o quanto cada variável determinou sua escolha pela IES. Este conjunto de variáveis resultou em 12 itens e cada um recebeu uma escala do tipo Likert de 5 pontos (Discordo totalmente, Discordo parcialmente, Nem concordo e nem discordo, Concordo parcialmente e Concordo totalmente).

Segundo Silva Júnior e Costa (2014), o modelo desenvolvido por Rensis Likert consiste em desenvolver um conjunto de afirmações relacionadas a cada variável, para as quais os respondentes darão seu grau de concordância. As variáveis influenciadoras foram elaboradas através das propostas por Ramos, Sander e Prado (2013) e Nascimento et al. (2014).

A amostra é formada por alunos do Curso de Ciências Contábeis de duas instituições da modalidade presencial e duas instituições da modalidade à distância. Foram coletadas respostas dos questionários de 202 alunos, porém 19 foram invalidados por causa da ausência de respostas e/ou alternativas marcadas em duplicidade. Assim, a amostra da pesquisa ficou sendo de 183 alunos. Para Hair 
Júnior et al. (2009), o nível desejado de uma amostragem é de 15 a 20 respondentes para cada variável independente, pois quando esse nível é alcançado, a amostra passa a ser representativa e os resultados podem ser generalizados.

\section{ANÁLISE DE DADOS}

\subsection{Análise do perfil dos alunos na modalidade presencial e a distância}

Foi analisado inicialmente o perfil dos alunos de Ciências Contábeis das modalidades presencial e a distância, de Petrolina-PE e Juazeiro-BA, como: idade, sexo, modalidade de ensino, categoria que cursaram ensino médio, atuação profissional, renda familiar e a formação dos pais.

Tabela 1 - Perfil dos estudantes de Ciências Contábeis das modalidades presencial e a distância

\begin{tabular}{|c|c|c|c|}
\hline Perfil & Alternativas & Respondentes & Percentagem \\
\hline \multirow{5}{*}{ Idade } & De 17 a 21 anos & 73 & $40 \%$ \\
\hline & De 22 a 26 anos & 55 & $30 \%$ \\
\hline & De 27 a 31 anos & 21 & $11 \%$ \\
\hline & De 32 a 36 anos & 18 & $10 \%$ \\
\hline & Acima de 37 anos & 16 & $9 \%$ \\
\hline \multirow{2}{*}{ Sexo } & Feminino & 95 & $52 \%$ \\
\hline & Masculino & 88 & $48 \%$ \\
\hline \multirow{2}{*}{ Modalidade de ensino } & Presencial & 113 & $62 \%$ \\
\hline & À distância (EaD) & 70 & $38 \%$ \\
\hline \multirow{2}{*}{ Cursou ensino médio } & Escola Particular & 29 & $16 \%$ \\
\hline & Escola Pública & 154 & $84 \%$ \\
\hline \multirow{5}{*}{ Atuação profissional } & Não trabalho & 43 & $23 \%$ \\
\hline & Estagiário & 11 & $6 \%$ \\
\hline & Trabalho escritório contábil & 17 & $9 \%$ \\
\hline & Trabalho empresa outro ramo & 95 & $53 \%$ \\
\hline & Autônomo/Empresário & 17 & $9 \%$ \\
\hline \multirow{5}{*}{ Renda familiar } & Até 3 salários mínimos & 125 & $68 \%$ \\
\hline & De 3 a 6 salários mín. & 45 & $25 \%$ \\
\hline & De 6 a 9 salários mín. & 9 & $5 \%$ \\
\hline & De 9 a 12 salários mín. & 2 & $1 \%$ \\
\hline & Acima de 12 salários mín. & 2 & $1 \%$ \\
\hline \multirow{4}{*}{ Formação dos pais } & Analfabetos & 12 & $7 \%$ \\
\hline & Fundamental ou Médio & 126 & $68 \%$ \\
\hline & Graduação & 42 & $23 \%$ \\
\hline & Mestrado & 3 & $2 \%$ \\
\hline
\end{tabular}

Fonte: Dados da pesquisa (2018) 
A amostra é composta em $52 \%$ pelo gênero feminino, uma tendência também observada nas pesquisas de (BRITTO et al., 2016; MONDINI et al., 2014; BERGAMO et al., 2008).

$\mathrm{Na}$ análise do perfil dos estudantes, observou-se que $70 \%$ dos alunos de Ciências Contábeis de Petrolina e Juazeiro têm entre 17 e 26 anos. Os estudantes estão distribuídos $62 \%$ na modalidade presencial e $38 \%$ na modalidade à distância.

Quanto à atuação profissional dos alunos, a maioria (53\%) trabalha em empresas de outros ramos. Destaque para apenas $9 \%$ por atuarem em escritório contábil. São 84\% egressos do Ensino Público, 68\% com Renda Familiar de até 3 salários mínimos e $68 \%$ dos alunos têm pais com formação entre o Ensino Fundamental e Médio.

\subsection{Análise das variáveis determinantes na modalidade presencial}

Na segunda parte, foi feita uma análise descritiva das variáveis determinantes para a escolha da Instituição de Ensino Superior, separando a modalidade presencial da modalidade à distância, demonstrando o quão cada variável influenciou a escolha dos estudantes e também se há relação entre os fatores determinantes para escolha e as variáveis socioeconômicas.

Foram analisadas as 12 variáveis determinantes na modalidade presencial, sendo separadas em grau de concordância e demonstradas em quantidade de respondentes (Tabela 2 ).

Tabela 2 - Variáveis determinantes na escolha da IES na modalidade presencial

\begin{tabular}{c|c|c|c}
\hline Variáveis Determinantes & $\begin{array}{c}\text { Grau de } \\
\text { Concordância }\end{array}$ & $\begin{array}{c}\text { Nem concordo e } \\
\text { nem discordo }\end{array}$ & $\begin{array}{c}\text { Grau de } \\
\text { Discordância }\end{array}$ \\
\hline Preferência própria & 93 & 8 & 12 \\
\hline Nome da instituição no mercado & 92 & 16 & 5 \\
\hline Tempo para estudo e frequência das \\
aulas & 84 & 23 & 6 \\
\hline Corpo docente e qualidade de ensino & 77 & 26 & 9 \\
\hline Grade curricular do curso & 75 & 29 & 20 \\
\hline Facilidade de ingresso na instituição & 59 & 34 & 38 \\
\hline Valor da mensalidade & 59 & 16 & 29 \\
\hline Indicação familiar ou de amigos & 58 & 26 & 24 \\
\hline Localização da instituição & 55 & 34 & 27 \\
\hline Marketing e propaganda & 52 & 34 & 35 \\
\hline Segurança do campus & 41 & 37 & 39 \\
\hline Indicação de facilidade das atividades & 36 & 38 & 9 \\
\hline avaliativas & & & \\
\hline
\end{tabular}

Fonte: Dados da pesquisa (2018) 
Dentre as variáveis determinantes para escolha da Instituição de Ensino Superior na modalidade presencial, para cursar Ciências Contábeis, as seis mais determinantes são:

1. Nome da instituição no mercado;

2. Preferência própria;

3. Tempo para estudo e frequência das aulas;

4. Corpo docente e qualidade de ensino;

5. Grade curricular do curso;

6. Facilidade de ingresso na instituição.

Para melhor demonstrar as informações, o Gráfico 1 na sequência apresenta os percentuais dos números nas escolhas pelos estudantes:

Gráfico 1 - Variáveis com maior grau de influência na escolha da IES na Modalidade Presencial

- Grau de Concordância $\quad$ Nem concordo e nem discordo $\quad$ Grau de Discordância

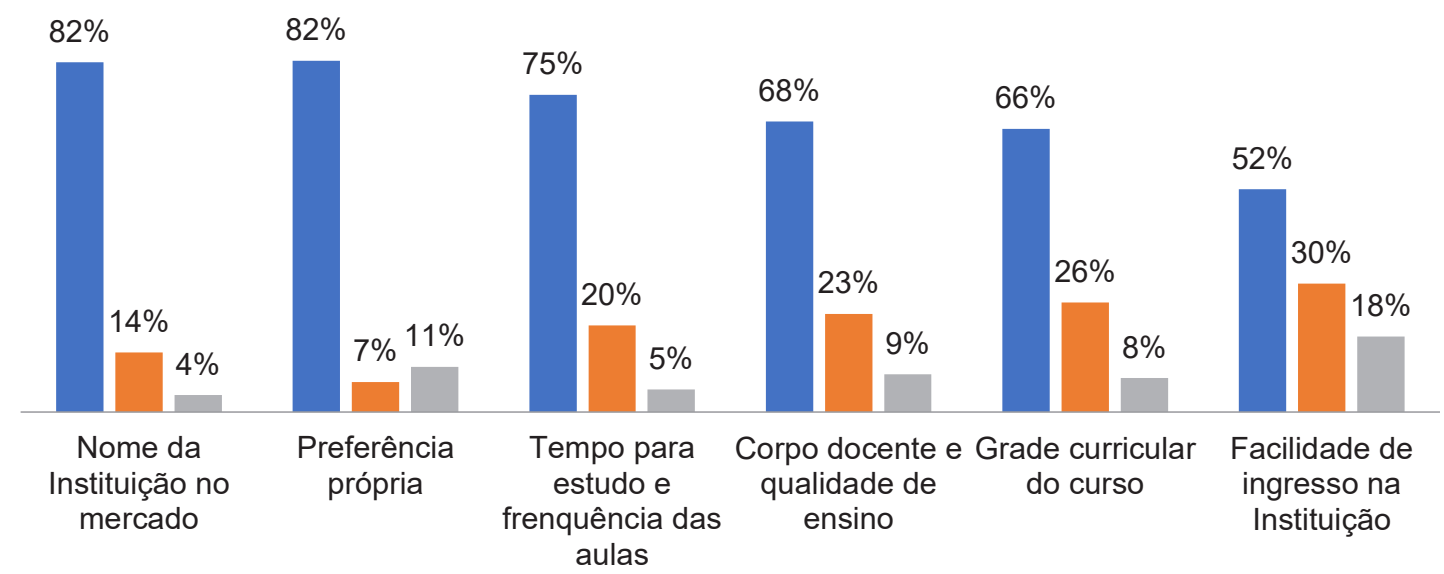

Fonte: Dados da pesquisa (2018)

Como se observa, o "Nome da instituição no mercado" com 82\% demonstra como é importante as instituições construírem um nome sólido e confiável no mercado, tendo em vista o quanto a variável foi determinante na escolha dos estudantes.

Em relação à "Preferência própria dos estudantes", também $82 \%$, notou-se que a maioria dos estudantes são independentes financeiros, pois $66 \%$ trabalham em alguma empresa ou são autônomos/empresários. 
Tabela 3 - Preferência Própria X Atuação Profissional

\begin{tabular}{c|c|c|c}
\hline \multirow{2}{*}{ Atuação Profissional } & \multicolumn{3}{|c}{ Preferência própria } \\
\cline { 2 - 4 } & $\begin{array}{c}\text { Grau de } \\
\text { Concordância 82\% }\end{array}$ & $\begin{array}{c}\text { Nem concordo e } \\
\text { nem discordo 7\% }\end{array}$ & $\begin{array}{c}\text { Grau de } \\
\text { Discordância } \\
\mathbf{1 1 \%}\end{array}$ \\
\hline Não trabalha & $29 \%$ & $38 \%$ & $33 \%$ \\
\hline Estagiário & $8 \%$ & $25 \%$ & $8 \%$ \\
\hline Trabalha escritório contábil & $13 \%$ & $0 \%$ & $8 \%$ \\
\hline $\begin{array}{c}\text { Trabalha empresa outro } \\
\text { ramo }\end{array}$ & $44 \%$ & $38 \%$ & $42 \%$ \\
\hline Autônomo/Empresário & $6 \%$ & $0 \%$ & $8 \%$ \\
\hline
\end{tabular}

Fonte: Dados da pesquisa (2018)

A variável "Tempo para estudo e frequência das aulas" tem um grau de concordância de $75 \%$ na modalidade presencial, demonstrando que os estudantes escolhem essa modalidade pelo maior tempo de estudo e pelas aulas serem diárias.

As variáveis "Corpo docente e qualidade de ensino", "Grade curricular do curso" e "Facilidade de ingresso na instituição" também são determinantes na escolha dos estudantes pela modalidade presencial, com um grau de concordância de $68 \%$, $66 \%$ e $52 \%$, respectivamente.

Destaque para "Facilidade de ingresso na instituição", demonstrando que os estudantes consideram fácil ingressar nas instituições da modalidade presencial da região.

As seis variáveis com menor grau de influência são apresentadas a seguir no Gráfico 2.

Gráfico 2 - Variáveis com menor grau de influência na escolha da IES na Modalidade

\section{Presencial}

" Grau de Concordância $\quad$ Nem concordo e nem discordo $\quad$ Grau de Discordância

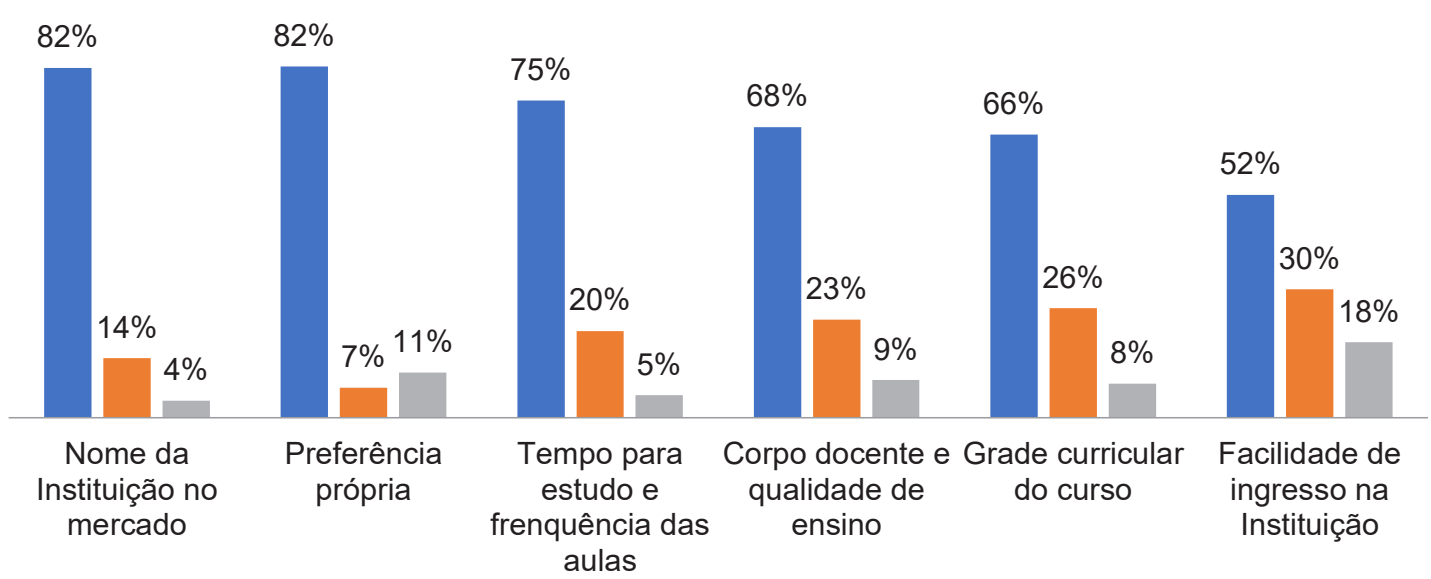

Fonte: Dados da pesquisa (2018) 
As variáveis com menor grau de influência são: "Valor da mensalidade" e "Indicação familiar ou de amigos" e tiveram um percentual de concordância de $52 \%$ e $51 \%$. As variáveis "Localização da instituição", "Marketing e propaganda", "Segurança do campus" e "Indicação de facilidade das atividades avaliativas" tiveram percentuais de concordância de $49 \%, 46 \%, 36 \%$ e $32 \%$, respectivamente.

\subsection{Análise das variáveis determinantes na modalidade a distância}

Foram analisadas as 12 variáveis determinantes na modalidade à distância, separadas em grau de concordância, sendo demonstrado em quantidade de respondentes na Tabela 4.

Tabela 4 - Variáveis Determinantes na Escolha da IES na Modalidade à Distância

\begin{tabular}{c|c|c|c}
\hline Variáveis Determinantes & $\begin{array}{c}\text { Grau de } \\
\text { Concordância }\end{array}$ & $\begin{array}{c}\text { Nem concordo e } \\
\text { nem discordo }\end{array}$ & $\begin{array}{c}\text { Grau de } \\
\text { Discordância }\end{array}$ \\
\hline Preferência própria & 62 & 7 & 1 \\
\hline Nome da Instituição no mercado & 57 & 9 & 4 \\
\hline Grade curricular do curso & 54 & 10 & 6 \\
\hline Localização da instituição & 52 & 9 & 10 \\
\hline Tempo para estudo e frequência das \\
aulas & 47 & 13 & 10 \\
\hline Facilidade de ingresso na instituição & 42 & 17 & 12 \\
\hline Corpo docente e qualidade de ensino & 40 & 17 & 9 \\
\hline Marketing e propaganda & 38 & 18 & 19 \\
\hline Indicação de facilidade das atividades \\
avaliativas
\end{tabular}

Fonte: Dados da pesquisa (2018)

As seis variáveis mais determinantes para escolha da IES pelos estudantes da EaD foram:

1- Preferência própria;

2- Nome da instituição no mercado;

3- Grade curricular do curso;

4- Localização da instituição;

5- Tempo para estudo e frequência das aulas;

6- Segurança do campus. 
O Gráfico 3 apresenta na sequência os percentuais de concordâncias para as variáveis:

Gráfico 3 - Variáveis com maior Grau de Influência na escolha da IES na Modalidade a Distância

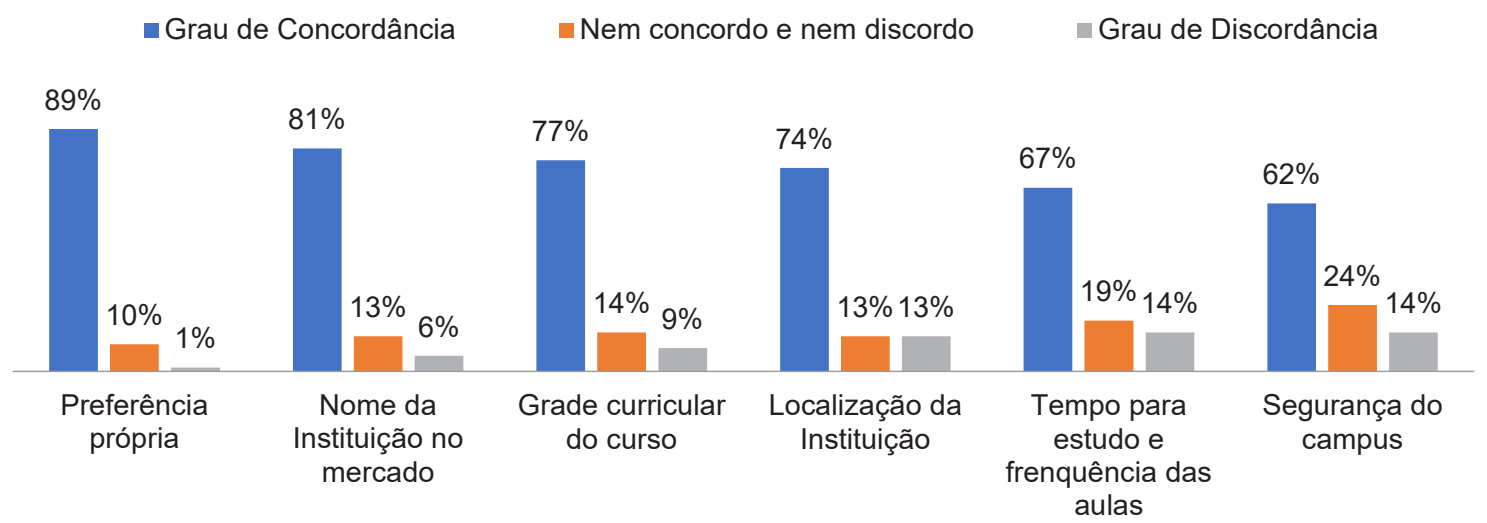

Fonte: Dados da pesquisa (2018)

Como se observa, os estudantes da EaD apontaram como determinantes para escolha da IES: "Preferência própria" (89\%), "Nome da instituição no mercado" (81\%), demonstrando que na região não há distinção entre as duas variáveis, confirmando a importância de um nome sólido no mercado.

As variáveis "Grade curricular do curso", "Localização da instituição", "Tempo para estudo e frequência das aulas" e "Segurança do campus" também são consideradas determinantes para essa escolha com 77\%, 74\%, 67\% e 62\%, respectivamente.

Destaque para as variáveis "Localização da instituição" e "Segurança do campus", tendo em vista que os estudantes dos cursos presenciais não consideram como as mais determinantes.

A variável "Tempo de estudo e frequência das aulas" foi determinante para $67 \%$ dos estudantes da EaD; já para os estudantes presenciais, esse grau de concordância foi $75 \%$, demonstrando que o fato das aulas serem apenas uma vez por semana não foi o maior determinante da escolha pelos cursos da EaD.

As seis variáveis com menor grau de influência observadas pelos estudantes da EaD estão apresentadas no Gráfico 4 a seguir: 
Gráfico 4 - Variáveis com menor grau de influência na escolha da IES na modalidade a distância

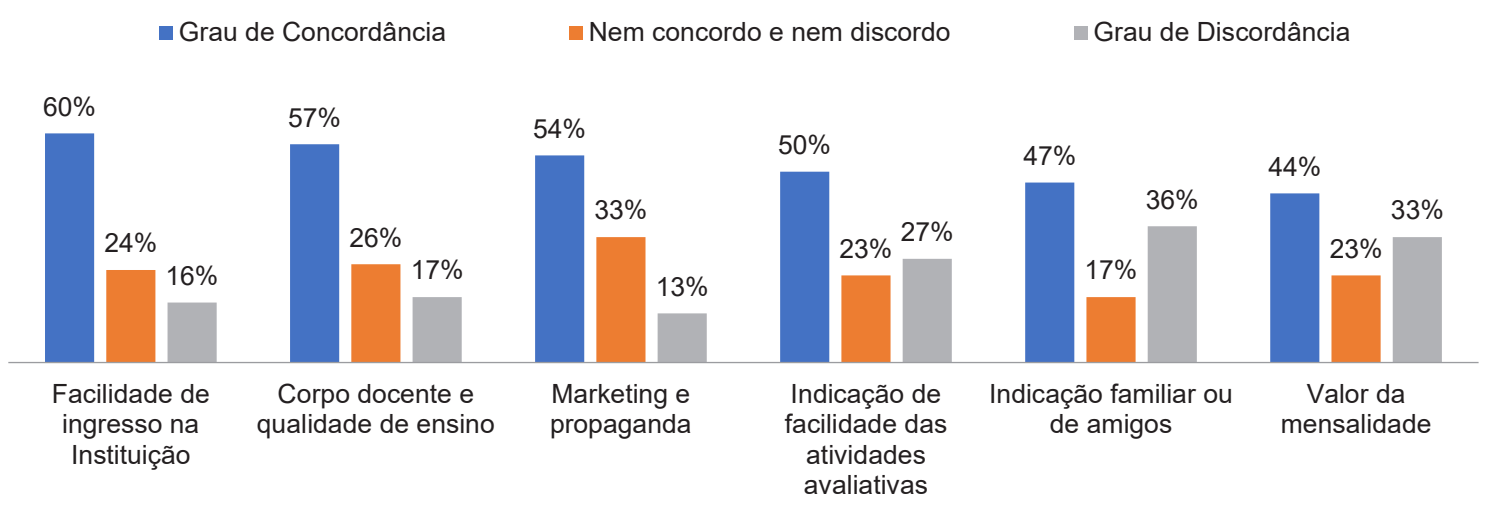

Fonte: Dados da pesquisa (2018)

Os percentuais das variáveis com menor grau de influência na escolha pelos estudantes da EaD foram: "Facilidade de ingresso na instituição", "Corpo docente e qualidade de ensino", "Marketing e propaganda" e "Indicação de facilidade das atividades avaliativas" com $60 \%, 57 \%, 54 \%$ e 50\%, respectivamente.

Destaque para a variável "Indicação de facilidade das atividades avaliativas" com $50 \%$, enquanto para alunos dos cursos presenciais foi de $32 \%$. Essa informação constitui-se como uma das influenciadoras para escolha dos cursos da EaD.

As variáveis "Facilidade de ingresso na instituição" e "Corpo docente e qualidade de ensino" tiveram percentuais próximos, porém a primeira foi maior $(60 \%)$ na observação dos alunos da EaD, enquanto a segunda foi $68 \%$, conforme estudantes dos cursos presenciais.

\section{CONSIDERAÇÕES FINAIS}

No intuito de identificar os determinantes para escolha da IES pelos estudantes do curso de Ciências Contábeis, a observação inicial desse estudo é que a ordem dos determinantes para as escolhas se altera entre os estudantes dos cursos presenciais e a distância.

Os estudantes das IES presenciais apontaram queas variáveis determinantes para a escolha do curso foram o Nome da instituição no mercado; Preferência própria; Tempo para estudo e frequência das aulas; Corpo docente e qualidade de ensino; Grade curricular do curso e Facilidade de ingresso na instituição. Já os estudantes dos cursos EaD apontaram a Preferência própria, seguida pelo Nome da instituição no mercado; Grade curricular; Localização da instituição; Tempo para estudo e frequência das aulas; Segurança do Campus.

A variável "Facilidade de ingresso", apesar de apontada pelos estudantes presenciais entre as mais determinantes para escolha da IES, teve o seu percentual de 
concordância menor que a opinião dos estudantes EaD. Questões como localização da IES e Segurança do Campus, apontadas pelos estudantes dos cursos EaD como relevantes, não foram apontadas pelos estudantes dos cursos presenciais. Neste caso, nota-se que a localização dos polos de ensino EaD e a segurança são relevantes para a escolha do curso.

Outra observação do estudo é que, enquanto os alunos cursos presenciais apontaram como determinante o corpo docente e qualidade de ensino, esta variável não foi apontada entre as mais determinantes pelos estudantes dos cursos EaD.

Sugere-se que os resultados aqui apontados possam ser utilizados no processo decisório das IES no que se refere às ações para captação de estudantes egressos do ensino médio e que desejam ingressar no ensino superior. Não diferente, serve para que os candidatos estudantes possam balizar suas escolhas.

Propõe-se, para trabalhos futuros, um estudo com estudantes de outras localidades para análise comparativa, tendo em vista que variáveis como tamanho populacional, economia, entre outras, possam interferir nas escolhas dos determinantes pelos estudantes.

\section{REFERÊNCIAS}

ALESSIO, S. C.; DOMINGUES, M. J. CA. DE S.; SCARPIM, J. E. Fatores determinantes na escolha por uma Instituição de Ensino Superior do Sul do Brasil. SEGeT - Simpósio de Excelência em Gestão e Tecnologia, v. VII, p. 01-14, 2013.

ALONSO, K. M. A expansão do ensino superior no Brasil e a EaD: dinâmicas e lugares. Educação \& Sociedade, v. 31, n. 113, p. 1319-1335, 2010.

ANDRADE, P. R. DE; ARAUJO, H. C. R. Análise do perfil dos estudantes de uma IES: o marketing como ferramenta para as instituições de ensino superior. Brazilian Business Review, v. 8, n. 1, p. 61-73, 2011.

BERGAMO, F. V. D. M. et al. De Prospect a Aluno: Fatores Influenciadores da Escolha de uma Instituição de Ensino Superior. Encontro de Marketing da ANPAD - Ema, v. III, p. 1-15, 2008.

BEUREN, I. M. Como elaborar trabalhos monográficos em contabilidade. 3. ed. São Paulo: Editora Atlas, 2006.

BORGES, G. D. R. et al. Instituições de Ensino Superior a Distância: Análise dos motivos de escolha. Meta: avaliacao, v. 6, n. 16, p. 71-84, 2014. 
BOSSA, A. G. Comportamento do consumidor educacional : atributos utilizados no processo decisório de compra de serviços educacionais na cidade de Maringá. Revista Eletrônica Do Mestrado Profissional Em Administração Da Unp, v. 6, n. 2, p. 9-21, 2014.

BRITTO, L. C. et al. Motivos da Escolha da Educação a Distância: O Aluno como Consumidor. Revista de Administração IMED, v. 6, n. 2, p. 206-220, 2016.

CHAVES, L. C. et al. Gestão do processo decisório: mapeamento ao tema conforme as delimitações postas pelos pesquisadores. Revista Estratégia \& Negócios, v. 5, n. 1, p. 03-27, 2012.

CRICCA, S. et al. A escolha de um curso superior de tecnologia da area de gestao e negocios: Um estudo sobre a decisao de compra e o comportamento do consumidor. Gestao and Regionalidade, v. 30, n. 89, p. 116-127, 2014.

DOMINGUES, M. J. C. de S. et al. A Relação entre o Perfil dos Alunos que Cursam EAD e os Motivos de Escolha desta Modalidade. Revista de Administração da Unimep, v. 14, n. 3, p. 80-101, 2016.

HAIR, J. F. et al. Análise multivariada de dados. Bookman Companhia Editora, v. Seção II, n. Capítulo 4, p. 01-682, 2009.

JORDANI, P. S. et al. Fatores determinantes na escolha profissional : um estudo com alunos concluintes do ensino médio da região Oeste de Santa Catarina. Revista ADMpg Gestão Estratégica, v. 7, n. 2, p. 25-32, 2014.

SILVA JUNIOR, D. DA S.; COSTA, F. J. Mensuração e Escalas de Verificação: uma Análise Comparativa das Escalas de Likert e Phrase Completion. Revista Brasileira de Pesquisas de Marketing, Opinião e Mídia, v. 15, p. 1-16, 2014.

MONDINI, V. E. D. et al. Análise dos fatores determinantes da escolha pela modalidade de ensino superior a distância em uma ies no sul do Brasil. SemeAd Seminários em Adinistração, v. XVII, p. 01-16, 2014.

NASCIMENTO, E. M. et al. Variáveis que Influenciam a Escolha dos Estudantes por Cursos de Pós-Graduação Lato Sensu a Distância na Área de Negócios. Revista de Educação e Pesquisa em Contabilidade, v. 8, n. 1, p. 73-95, 2014.

PORTUGAL, N. DOS S. et al. Educação a distância - valores que norteiam a escolha. Revista Gestão Organizacional, v. 6, n. 1, p. 93-104, 2013.

PUERTA, A. A.; AMARAL, R. M. Comparação da educação presencial com a educação à distância através de uma pesquisa aplicada. Seminário de Bibliotecas Universitárias-São paulo, v. XV, p. 01-14, 2008. 
RAMOS, S. C.; SANDER, J. A.; PRADO, P. H. M. Processo Decisório para Escolha de uma Instituição de Ensino Superior: Dimensões da Decisão e Fatores Relevantes. Encontro da ANPAD - EnANPAD, v. XXXVII, p. 1-14, 2013.

REIS, E. DOS; LOBLER, M. L. O processo decisório descrito pelo indivíduo e representado nos sistemas de apoio à decisão. Revista de Administração Contemporânea, v. 16, n. 3, p. 397-417, 2012.

SCHARF, E. R.; SCARPIN, M. R. S. A importância da marca da instituição de ensino superior na escolha de um curso de pós-graduação lato sensu. Revista Cesumar Ciências Humanas e Sociais Aplicadas, v. 19, n. 2, p. 241-260, 2014.

SCHINAIDER, A. D. et al. Comportamento do consumidor educacional: seu perfil e o processo de tomada de decisão. Future Studies Research Journal, v. 8, n. 2, p. 149-170, 2016.

SCHMIDT, P. et al. Perfil dos alunos do curso de ciências contábeis de instituições de ensino do sul do Brasil. Revista ConTexto, v. 12, n. 21, p. 87-104, 2012.

TANEGUTI, L. Y. Relatório técnico contendo estudo sobre a atual relação oferta/ demanda de cursos de graduação no Brasil, como subsídio ao Conselho Nacional de Educação para a formulação de políticas públicas que possibilitem a melhor distribuição da oferta de vagas no en. Ministério da Educação, Projeto CNE/Unesco, v. 04, p. 01-48, 2008.

\section{BIOGRAFIA DOS AUTORES}

DJANDA COELHO DE ASSIS - Graduada em Ciências Contábeis pela Faculdade de Ciências Sociais de Petrolina - FACAPE.

JOSAIAS SANTANA DOS SANTOS - Doutorando em Ciências Contábeis pela Universidade de Brasília - UNB, Mestre em Ciências Contábeis pela FUCAPE, Professor da Faculdade de Ciências Sociais de Petrolina - FACAPE.

FLORISVALDO CUNHA CAVALCANTE JÚNIOR - Mestre em Controladoria pela Universidade Federal Rural de Pernambuco - UFRPE, Professor do Instituto Federal do Sertão de Pernambuco (IF SERTÃO - PE).

JOÃO EUDES DE SOUZA CALADO - Mestre em Ciências Contábeis pela FUCAPE, Técnico Administrativo da Universidade Federal do Vale do São Francisco - UNIVASF.

Data de recebimento: 01/09/2020

Data de aprovação: 29/10/2020 